\title{
NUMERICAL INVESTIGATION OF FORCED CONVECTION OF NANOFLUID IN MICROCHANNELS HEAT SINKS
}

\author{
A. Belhadj ${ }^{1, *}$, R. Bouchenafa ${ }^{2}$, R. Saim ${ }^{2}$
}

\begin{abstract}
This paper presents a numerical study of laminar forced convective flow of nanofluid-based water $/ \mathrm{Al}_{2} \mathrm{O}_{3}$ in a two-dimensional horizontal microchannel heat sink. The governing equations are solved by using the finite volume method based on simple algorithm. The effect of solid nanoparticles on the heat transfer is investigated after comparing our results with experimental data. The founding results showed that the use of nanofluid has enhanced the heat transfer in comparison with pure fluid, and the increasing of $\mathrm{Al}_{2} \mathrm{O}_{3}$ concentration enhances the thermal and dynamic parameters. Nusselt number and friction coefficient have been enhanced with the increasing of Reynolds number. This work contributes to ameliorate the cooling systems by integrating the nanofluids in the next generation of microchannels heat sinks.
\end{abstract}

\section{Keywords: Forced Convection, Nanofluid, Heat Transfer, Microchannels, $\mathrm{Al}_{2} \mathrm{O}_{3}$, Nanoparticles}

\section{INTRODUCTION}

Miniaturization of electronic devices has revolutionized the industrial world, which become an open field for researchers and engineers to devote countless efforts in new applications, this miniaturization has increased the heat flux density of electronic devices, the challenge was to maintain these devices in the safe range to maintain their performance. This challenge was acquired using MEMS (Micro Electro Mechanical Systems) which are the ultimate choice for thermal management control, in particularly microchannels heat sinks: one of the most feasible applications of MEMS. Tuckerman and Pease [1] examined microchannels heat sinks for the first time in 1981; they showed that a good heat dissipation rate can assured using a simple microchannel.

Forced convection has been widely investigated in microchannels heat sinks; Chai et al. [2] studied the pressure drop and heat transfer characteristics of the interrupted microchannel heat sink with rectangular ribs in the transverse micro chambers. Weilin et al. [3] studied the flow in trapezoidal microchannels with hydraulic diameters of 51 and $169 \mu \mathrm{m}$, they showed a significant difference between the experimental results and theory. Gururatana [4] numerically studied forced convective flow in microchannel heat sink with dimples, he showed the effect of dimples on heat transfer enhancement, by increasing average Nusselt number, and he concluded that dimples are useful when Reynolds number is greater than 125. Belhadj et al. [5, 6] studied the laminar forced convective flow in microchannels heat sinks with periodic expansion-constriction cross section; they showed that the added cross sections with cylindrical groves and triangular cavities have enhanced the heat transfer performance.

Recently, the progress of material engineering conducts to another smart technology, using nano-sized particles dispersed to a fluid, Masuda et al. [7] have the head start for this technique, they have shown that it is possible to break down the limits of conventional solid particle suspensions by conceiving the concept of nanoparticle-fluid suspensions. These nanoparticle-fluid suspensions are termed nanofluids, obtained by dispersing nanometer-sized particles in a conventional base fluid like water, oil, and ethylene glycol etc. In 1995, Choi [8] proposed the name of nanofluid for this invention, many researches are made using nanofluids in microchannels heat sinks. Pak and Cho [9] investigated for the first time the turbulent forced convective flow of $\gamma-\mathrm{Al}_{2} \mathrm{O}_{3} /$ water and $\mathrm{TiO} 3 /$ water in circular tube; they remarked a heat transfer enhancement obtained with $\gamma$ $\mathrm{Al}_{2} \mathrm{O}_{3} /$ water, higher than that of TiO3/ water, finally they proposed a new correlation for Nusselt number. Das et al. [10] have observed increases of $10-25 \%$ in water with $1-4$ volume $\%$ alumina nanoparticles. In addition, it appears that thermal conductivity of nanofluids is a strongly increasing function of temperature, much more so than that of pure liquids. Lie Jie [11] in his PhD thesis studied the three-dimensional microchannels heat sinks using nanofluids; he found that nanofluids do measurably enhance the thermal performance of microchannel mixture flow with a small increase in pumping power. Specifically, the thermal performance increases with volume This paper was recommended for publication in revised form by Regional Editor Mohamed Awad

${ }^{1}$ MECACOMP Laboratory, Department of Mechanical Engineering, Tlemcen University, Tlemcen, Algeria

${ }^{2}$ ETAP Laboratory, Department of Mechanical Engineering, Tlemcen University, Tlemcen, Algeria

${ }^{*} E$-mail address: belhabdelkadir@gmail.com

Manuscript Received 21 January 2017, Accepted 3 May 2017 
fraction; but, the extra pressure drop, or pumping power, will somewhat decrease the beneficial effects. Microchannels heat sinks with nanofluids are expected to be good candidates for the next generation of cooling devices. Raisi et al. [12] studied numerically the forced convection of laminar nanofluid $\mathrm{Cu} / \mathrm{water}$, the numerical results indicate that the heat transfer rate is significantly affected by the solid volume fraction and slip velocity coefficient at high Reynolds numbers. Murshed et al. [13] studied experimentally the forced convective TiO2/DIW-based nanofluids flowing through a minichannel under laminar flow and constant heat flux conditions, the results showed that nanofluids exhibits considerably enhanced convective heat transfer coefficient, which also increases with volumetric loadings of $\mathrm{TiO} 2$ nanoparticles. For example, at 0.8 volume $\%$ of nanoparticles and at position $\mathrm{x} / \mathrm{Di}=25$ (where tube diameter $\mathrm{Di}=4 \mathrm{~mm}$ ), the local heat transfer coefficient of this nanofluid was found to be about $12 \%$ and $14 \%$ higher compared to deionized water at Re of 1100 and 1700 , respectively. Izadi et al. [14] studied the thermal and the hydrodynamic indexes of nanofluid flow in microchannels heat sinks, they compared the numerical results with analytical and experimental results, their results showed that the pressure decreases when the brinkman number increases. Rashidi et al. [15] have done a comparative numerical study of two-phase models of nanofluid heat transfer. They showed that for the two-phase models, the increasing of volume fraction has enhanced the heat transfer coefficient only for low values of Reynolds number, while for the singlephase model, the enhancement is ensured for all Reynolds number.

Many nanoparticles have been employed as nanofluids to enhance the thermal conductivity of fluids; Carbon nanotubes have been used by Estellé [16] et al. to investigated experimentally the thermal performance of water, they have observed that thermal condictuvity enhancement of CNT nanofluids increase with volume fraction and temperature. The thermal conductivity enhancement is really significant at very low volume fraction, in particular at 30 and $40^{\circ} \mathrm{C}$. Kherbeet et al. [17] investigated experimentally the effects of laminar nanofluid flow over the microscale backward- facing step (MBFS) and forward-facing step (MFFS) on the heat transfer characteristics, the experimental results revealed that the concentration of 0.01 water-SiO2 nanofluid recorded the highest Nusselt number. The comparison between MBFS and MFFS revealed that the highest Nusselt number is obtained with the MFFS, which is approximately twice that of MBFS. Kalteh [18] investigated numerically and experimentally the nanofluid forced convection inside a wide microchannel heat sinks. Ilhan and Ertürk [19] studied experimentally the laminar forced convection of a hexagonal boron nitride-water nanofluid in a circular pipe, they showed the enhancement in the convective heat transfer coefficient of hBN-water nanofluids is proportional to the observed thermal conductivity enhancement.

Moreover, $\mathrm{Li}$ [20] investigated the heat transfer enhancement and entropy generation of $\mathrm{Al}_{2} \mathrm{O}_{3}$-water nanofluids laminar convective flow in the microchannels with flow control devices (cylinder, rectangle, protrusion, and v-groove), the effects of the geometrical structure of the microchannel, nanofluids concentration $\phi \mathrm{j}(0 \%-3 \%)$, and Reynolds number $\operatorname{Re}(50-300)$ were comparatively studied by means of performance parameters. The obtained results showed a significant enhancement of friction ratio, Nusselt number ratio and relative entropy generation. Nanofluids have been widely used for the cooling high generation computer processors. Many researches [21, 22, $23]$ have been devoted to prove the efficiency of nanofluid in heat transfer enhancement.

In this paper, the laminar forced convection of nanofluid water/AL2O3 is investigated inside microchannels heat sinks for Reynold number ranging from 150 to 1500 . The mathematical modelling of nanofluid flow is presented, the average Nusselt number and friction coefficient is discussed for different concentrations of $\mathrm{A} 12 \mathrm{O} 3$.

\section{MATHEMATICAL MODELLING}

The physical model is a horizontal microchannel heat sink having a length $\mathrm{L}=4 \mathrm{~mm}$, and the height $\mathrm{H}=0.2 \mathrm{~mm}$, the nanofluid enters the microchannels by an inlet uniform speed $\mathrm{U}$ at a relatively low constant temperature $\mathrm{T}=300 \mathrm{~K}$, Status conditions are considered stable and the flow of nanofluid is assumed to be laminar and incompressible. The solid nanoparticles of $\mathrm{Al}_{2} \mathrm{O}_{3}$ is assumed to flow by a constant speed and in thermal equilibrium. The Figure. 1 illustrates the geometry of the physical problem. It is noticed that every channel with a diameter $\mathrm{D} \leq 0.2 \mathrm{~mm}$ is considered as a microchannel.

The Navier-Stokes and energy equations are used to model the convective heat transfer process with the following assumptions: Two-dimensional, incompressible, laminar and in steady state. The effect of gravity and 
other forms of body forces are negligible. The properties can be considered as constant because of the narrow temperature range. The continuity, momentum and energy equations for laminar flow of water $/ \mathrm{Al}_{2} \mathrm{O} 3$ nanofluid can be listed as Eq. 1-4 [25]:

Continuity equation:

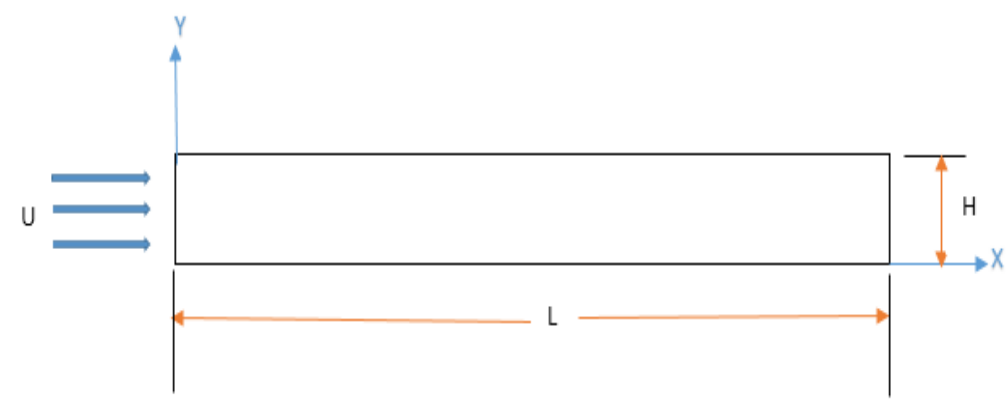

Figure 1. The Physical Geometry of the problem.

$$
\frac{\partial u}{\partial x}+\frac{\partial v}{\partial y}=0
$$

Momentum equation:

$$
\begin{gathered}
u \frac{\partial u}{\partial x}+v \frac{\partial u}{\partial y}=\frac{1}{\rho_{n f}}\left[-\frac{\partial p}{\partial x}+\mu_{n f}\left(\frac{\partial^{2} u}{\partial x^{2}}+\frac{\partial^{2} u}{\partial y^{2}}\right)\right] \\
u \frac{\partial v}{\partial x}+v \frac{\partial v}{\partial y}=\frac{1}{\rho_{n f}}\left[-\frac{\partial p}{\partial y}+\mu_{n f}\left(\frac{\partial^{2} v}{\partial x^{2}}+\frac{\partial^{2} v}{\partial y^{2}}\right)\right]+(\rho \beta)_{n f} g\left(T-T_{0}\right)
\end{gathered}
$$

Energy equation:

$$
u \frac{\partial T}{\partial x}+v \frac{\partial T}{\partial y}=\alpha_{n f}\left(\frac{\partial^{2} T}{\partial x^{2}}+\frac{\partial^{2} T}{\partial y^{2}}\right)
$$

where: $\alpha_{n f}=\frac{K_{n f}}{(\rho C p)_{n f}}$

By introducing the nanofluid solid volume fraction $\Phi$, the viscosity of the nanofluid is computed as:

$$
\mu_{n f}=\mu_{f}(1-\phi)^{-2.5}
$$

The other thermophysical properties are calculated as following:

$$
\rho_{n f}=(1-\phi) \rho_{f}+\phi \rho_{s}
$$




$$
\begin{gathered}
\left(\rho c_{p}\right)_{n f}=(1-\phi)\left(\rho c_{p}\right)_{f}+\phi\left(\rho c_{p}\right)_{s} \\
(\rho \beta)_{n f}=(1-\phi)(\rho \beta)_{f}+\phi(\rho \beta)_{s}
\end{gathered}
$$

The thermal conductivity is assumed by Maxwell-Garnet's model as:

$$
k_{n f}=k_{f}\left[\frac{\left(k_{s}+2 k_{f}\right)-2 \phi\left(k_{f}-k_{s}\right)}{\left(k_{s}+2 k_{f}\right)+\phi\left(k_{f}-k_{s}\right)}\right]
$$

Boundary conditions

$\mathrm{u}=\mathrm{v}=0$ and $\mathrm{T}=350 \mathrm{~K}$ for $\mathrm{y}=0$ and $0 \leq \mathrm{x} \leq \mathrm{L}$

$\mathrm{u}=\mathrm{v}=0$ and $\mathrm{T}=300 \mathrm{~K}$ for $\mathrm{y}=\mathrm{H}$ and $0 \leq \mathrm{x} \leq \mathrm{L}$

$\mathrm{u}=\mathrm{U}=3 \mathrm{~m} \cdot \mathrm{s}^{-1}, \mathrm{v}=0$ and $\mathrm{T}=300 \mathrm{~K}$ for $\mathrm{x}=0$ and $0 \leq \mathrm{y} \leq \mathrm{H}$

$\partial \mathrm{u} / \partial \mathrm{x}, \partial \mathrm{v} / \partial \mathrm{x}$ and $\partial \mathrm{T} / \partial \mathrm{y}=0$ for $\mathrm{x}=\mathrm{L}$ and $0 \leq \mathrm{y} \leq \mathrm{H}$

The dimensionless numbers: Reynolds number, Nusselt number and friction coefficient respectively are defined as:

$$
\begin{gathered}
R e=\frac{\rho U_{i n} D_{h}}{\mu} \\
N u=\frac{h \cdot D_{h}}{\lambda} \\
f=\frac{2 \cdot \Delta P \cdot D_{h}}{\rho U_{\text {in }}{ }^{2} L}
\end{gathered}
$$

The Table 1 gives the thermophysical properties of $\mathrm{Al}_{2} \mathrm{O}_{3}$ nanoparticle and the base fluid (water), which are used to determinate these of mixture that makes water $/ \mathrm{Al}_{2} \mathrm{O}_{3}$ nanofluid.

Table 1. Thermophysical properties of nanoparticle and base fluid at $\mathrm{T}=300 \mathrm{~K}$.

\begin{tabular}{|c|c|c|}
\hline $\begin{array}{c}\text { Thermophysical } \\
\text { properties }\end{array}$ & $\mathrm{Al}_{2} \mathrm{O}_{3}$ & Water \\
\hline$\rho\left(\mathrm{kg} / \mathrm{m}^{3}\right)$ & 3600 & 996.5 \\
\hline $\mathrm{Cp}(\mathrm{J} / \mathrm{kg} \mathrm{K})$ & 765 & 4181 \\
\hline $\mathrm{k}(\mathrm{W} / \mathrm{m} \mathrm{K})$ & 36 & 0.613 \\
\hline$\mu(\mathrm{Ns} / \mathrm{m} 2)$ & - & $1 \mathrm{E}-03$ \\
\hline
\end{tabular}


Table 2. Thermophysical properties of water $/ \mathrm{Al}_{2} \mathrm{O}_{3}$ nanofluid at $\mathrm{T}=300 \mathrm{~K}$

\begin{tabular}{|c|c|c|c|c|c|}
\hline Properties & $0 \%$ & $1 \%$ & $2 \%$ & $3 \%$ & $4 \%$ \\
\hline$\rho\left(\mathrm{kg} / \mathrm{m}^{3}\right)$ & 998.2 & 1024.218 & 1050.236 & 1076.254 & 1102.272 \\
\hline $\mathrm{Cp}(\mathrm{J} / \mathrm{kgK})$ & 4182 & 4061.8966 & 3947.744 & 3839.1106 & 3735.6056 \\
\hline$\lambda(\mathrm{W} / \mathrm{mK})$ & 0.6 & 0.685862854 & 0.766868859 & 0.843021037 & 0.91432296 \\
\hline$\mu\left(\mathrm{N} . \mathrm{s} / \mathrm{m}^{2}\right)$ & 0.001003 & 0.001132484 & 0.001308506 & 0.001553838 & 0.001916924 \\
\hline
\end{tabular}

\section{NUMERICAL METHOD AND CODE VALIDATION}

The numerical research has been carried out on the laminar steady forced convection heat transfer in a two-dimensional microchannel. The Reynolds number $(\mathrm{Re})$ varies from 150-1500 and the nanofluid volume fraction $(\phi)$ changes from $1-4 \%$ for both block geometries.

The simulations were performed using the FLUENT 6.3.26 software. The code were discretized by the second order upwind differencing scheme, decoupling with the SIMPLEX algorithm and solved using a finite volume approach. For the numerical method, Finite Volume Method is appropriated for fluid equations discretization, because of its rapidity and efficiency in solving the algebraic equations system.

Residual errors: continuity, momentum and energy equations are illustrated in Figure 2 where the convergence criteria of iterative solution have been insured when the residual of all variables are less than specific values $10-4$.

The 2D baseline microchannel heat sink is meshed using structure and un-structured shaped mashing refinement. The effect of mesh on the axial velocity is presented in Figure 3, which shows the insurance of grid independence of results for many tested mesh sizes, the parabolic shape of the velocity profile is ensured. Table 1 gives the stream function and the average Nusselt number for different meshing sizes, which give converged values, the CPU time is also presented in this table. A grid meshing size of 9264 nodes is adopted for the study.

The accuracy of our results was verified by comparing with experimental results done by Kalteh et al. [15] who gives the average Nusselt number of a nanofluid-forced convection inside a wide microchannel heat sink for a Reynolds number ranging from 50 to 250. It is clearly remarkable that our calculated Nusselt number of nanofluid flow $(\phi=1 \%)$ adapted in comparison with the experimental values (Figure.4).

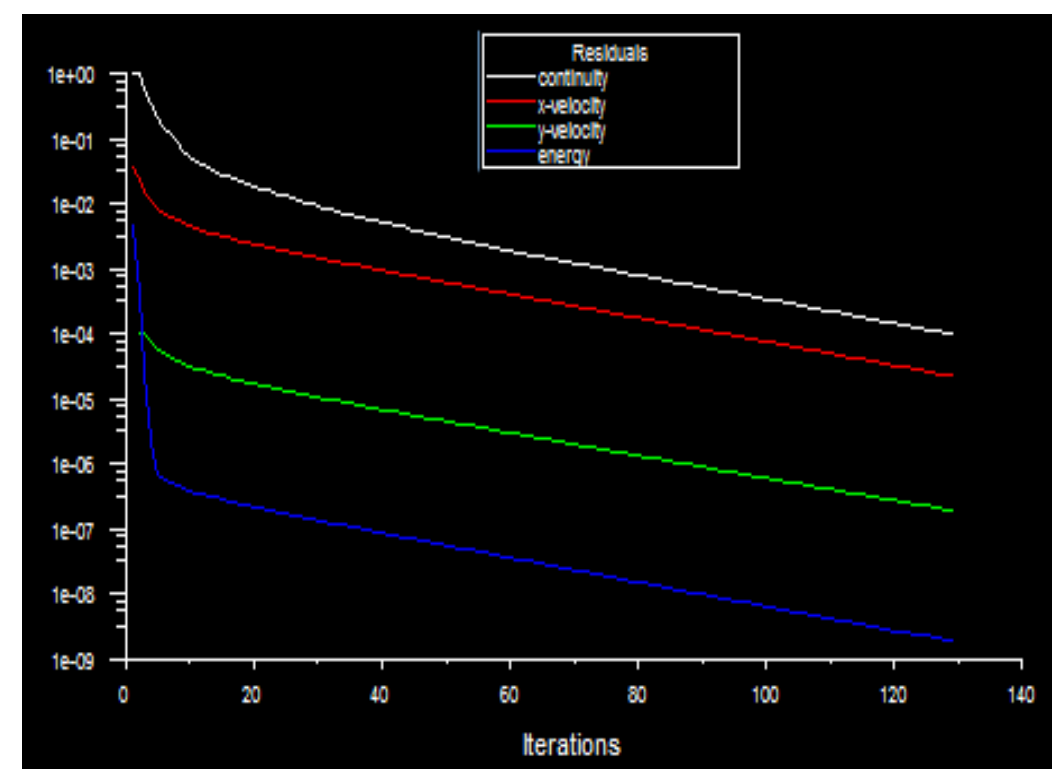

Figure 2. Residual errors (continuity, momentum and energy equations) 
Journal of Thermal Engineering, Research Article, Vol. 4, No. 5, pp. 2263-2273, July, 2018

Table 3. Dependence of the properties on the meshing size $(X=2.5 \mathrm{~mm})$

\begin{tabular}{|c|c|c|c|c|}
\hline & 8574 nodes & 9162 nodes & 9264 nodes & 9488 nodes \\
\hline$\Psi$ & 0.0003698 & 0.0003698 & 0.000355 & 0.000355 \\
\hline $\mathrm{Nu}$ & 8.321 & 8.323 & 8.325 & 8.325 \\
\hline $\mathrm{CPU}$ time & 8.13 & 8.13 & 8.13 & 8.13 \\
\hline
\end{tabular}

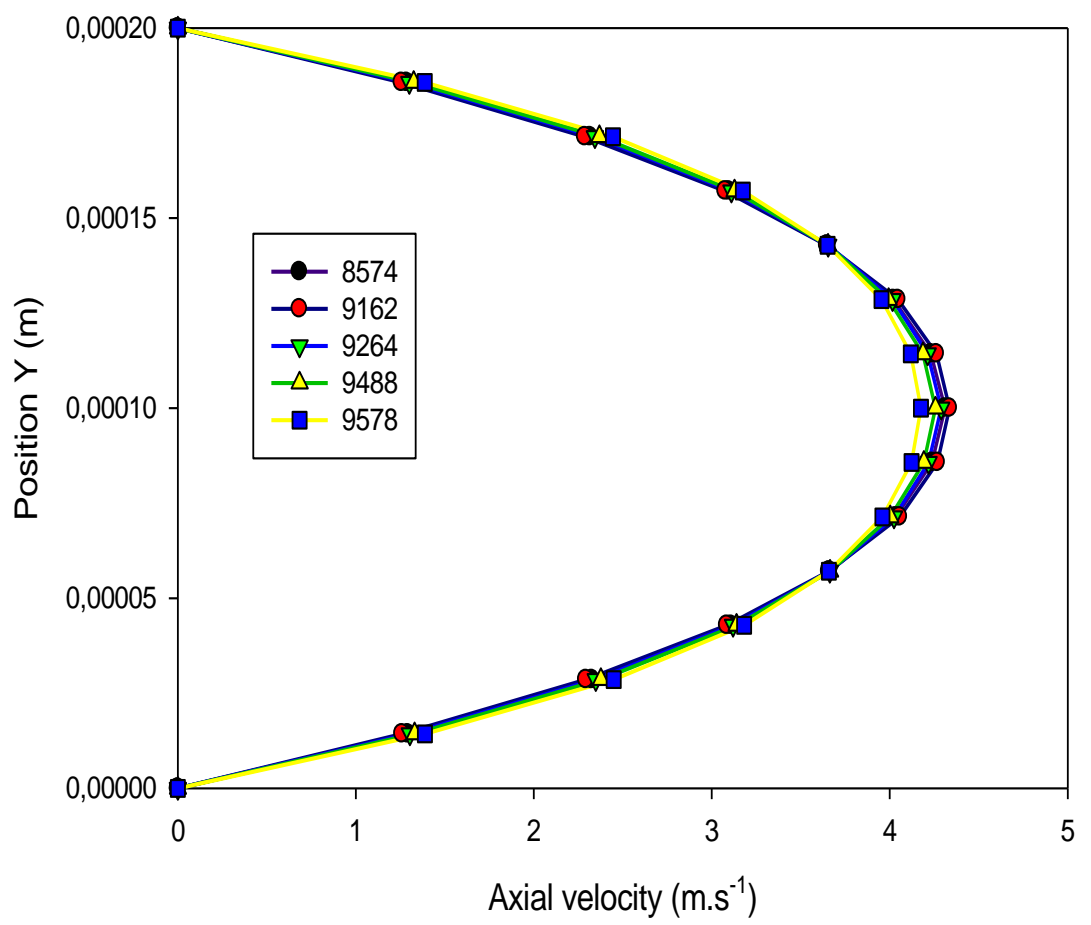

Figure 3. Axial velocity of nanofluid inside microchannels at $x=2.5 \mathrm{~mm}$

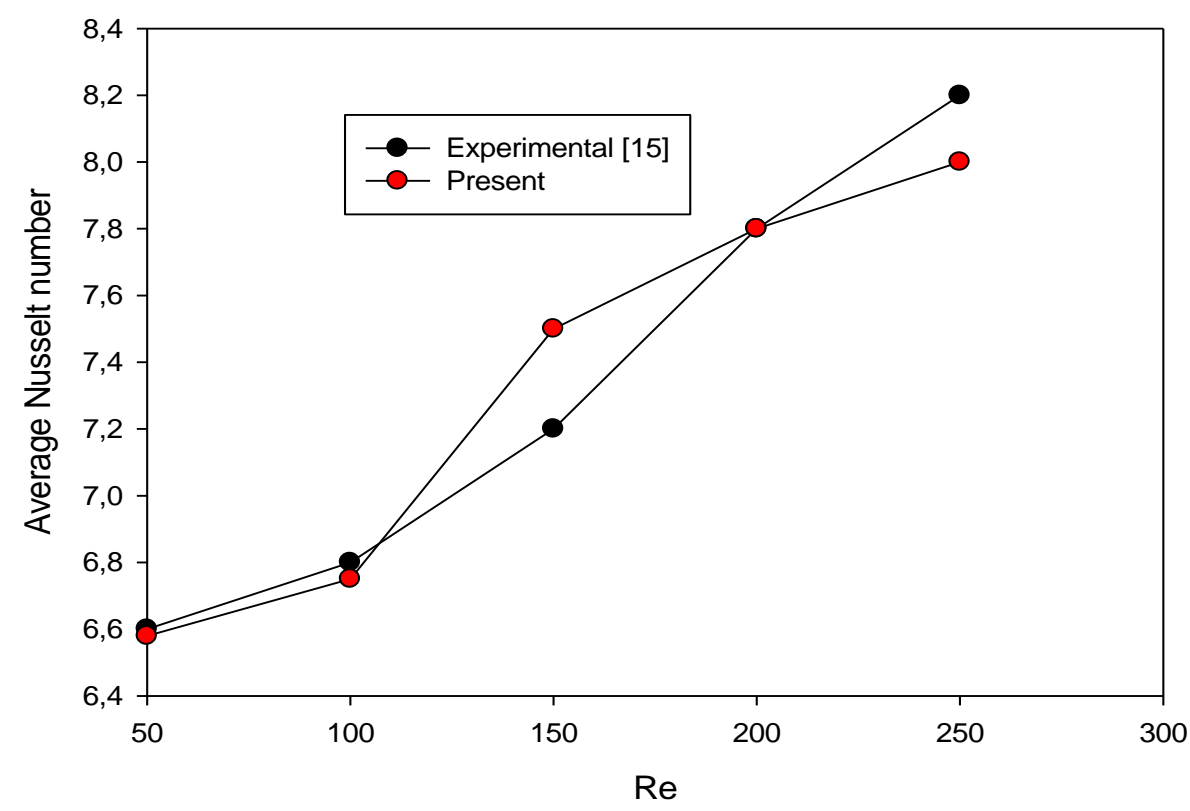

Figure 4. Comparison of the average Nusselt number with experimental results $(\phi=1 \%)$. 


\section{RESULTS AND DISCUSSION}

In this section, numerical results were presented to show the effect of nanoparticles concentration on the thermal and dynamic performance of forced convective flow inside microchannels heat sinks: axial velocity, average Nusselt number and friction coefficient have been discussed.

Figure.5. (a) presents the longitudinal velocity distribution of nanofluid in microchannel at $\mathrm{Re}=500$. It is found that the flow velocity at the middle reaches its maximum value $(6.5 \mathrm{~m} / \mathrm{s})$, and it is canceled near of the walls. The part (b) presents the velocity vectors of the flow.

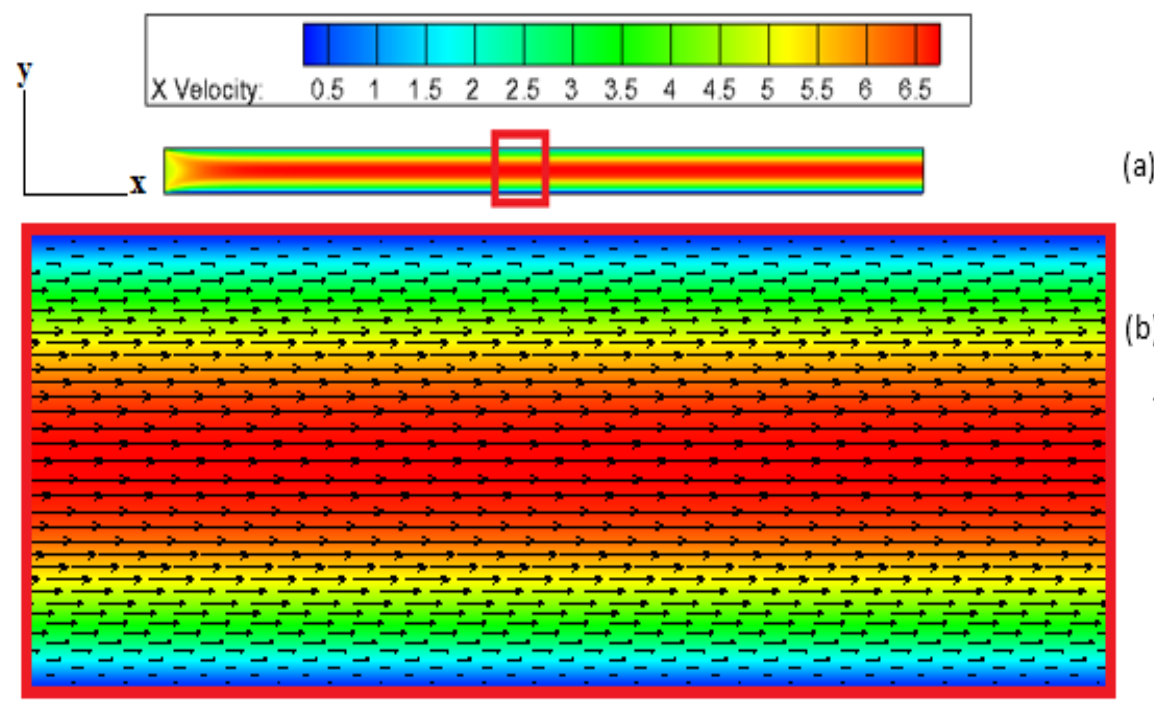

Figure 5. (a) Velocity contour. (b) Velocity vectors

The Figure 6 illustrates the axial velocity of flow for both pure water and nanofluid in order to investigate the parabolic streamlined curve of the flow.

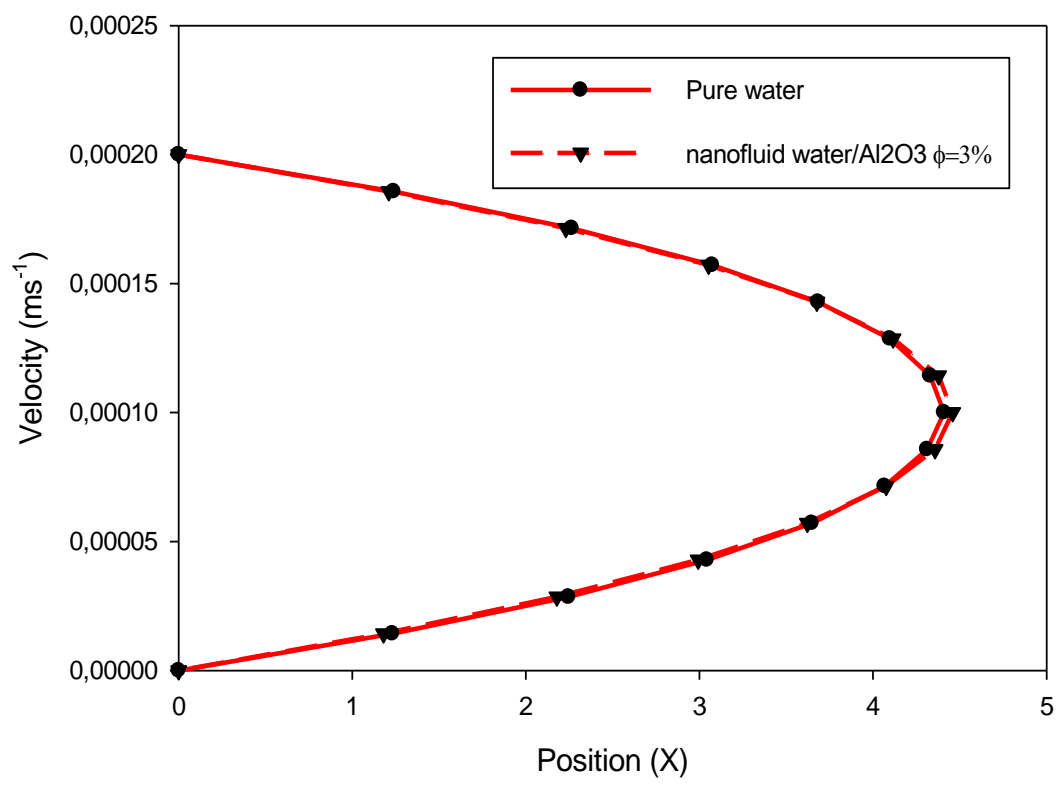

Figure 6. Axial velocity of pure water and nanofluid water $/ \mathrm{Al}_{2} \mathrm{O}_{3}$ versus the microchannel length 


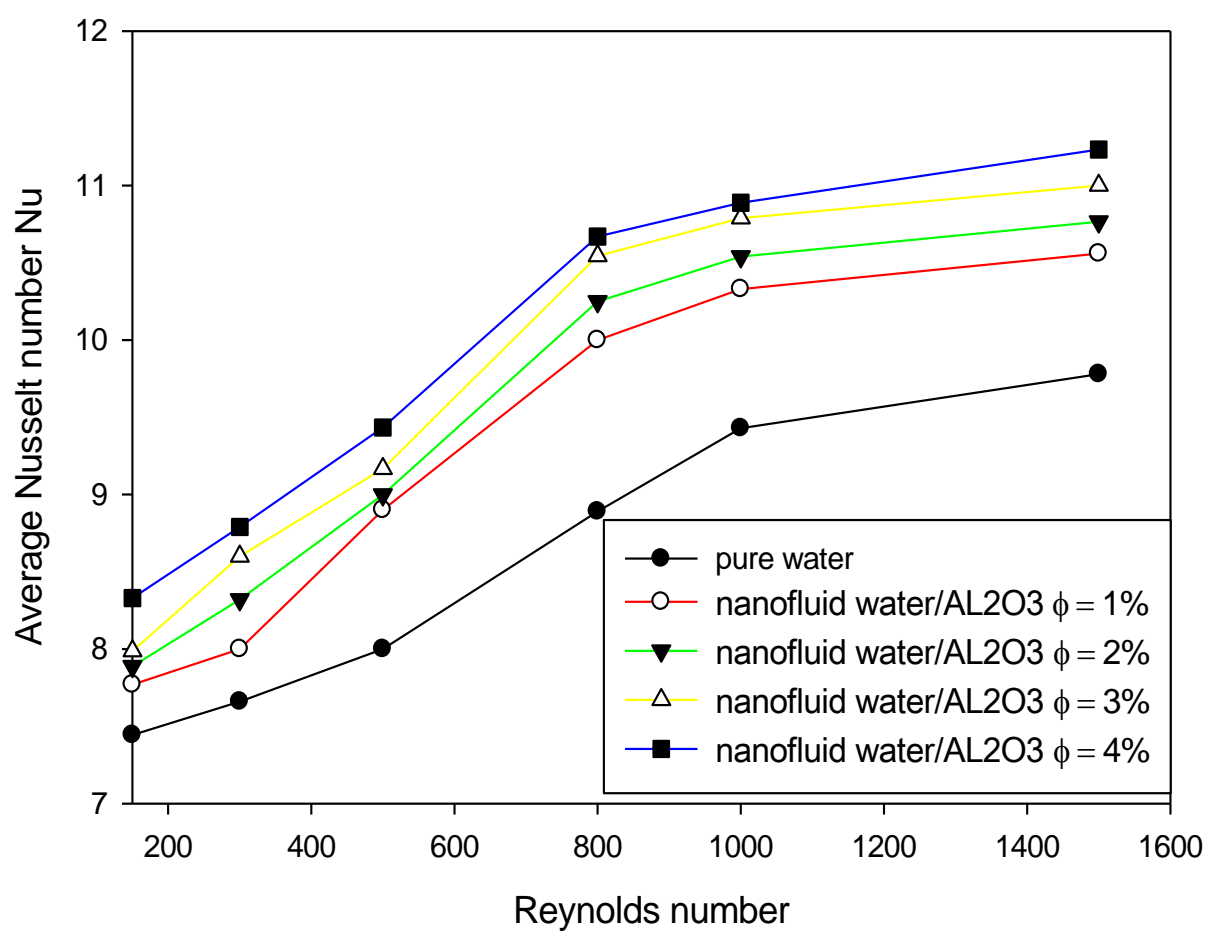

Figure 7. The variation of average Nusselt number with Reynolds number.

The variation of Nusselt number for different nanoparticles concentrations $\phi$ is illustrated in figure.7, which shows that the Nusselt number increases with the increase of Reynolds number; the increase of nanoparticles concentration $\phi$ has enhanced the Nusselt number which is higher than that of pure water, these remarks shew the effect of nanoparticles concentration on the Nusselt number.

Figure. 8 shows the temperature contour of water without and with $\mathrm{Al}_{2} \mathrm{O}_{3}$ nanoparticles inside a microchannel, it is clearly remarkable that the layer of high temperatures of water with $\mathrm{Al}_{2} \mathrm{O}_{3}$ is wider than that of pure water; this is due to the capitation of calories by $\mathrm{Al}_{2} \mathrm{O}_{3}$ nanoparticles.

The effect of nanoparticles concentration on the friction coefficient is presented in the figure.9, which illustrates the variation of the ratio $\mathrm{f} / \mathrm{f} 0$. For the nanofluid, the increase of Reynolds number and the nanoparticles concentration enhanced the friction coefficient ratio; this is due to the interaction of the fluid with nanoparticles that pick up more calories from the hot source through the basic fluid. For Reynolds number higher than 1000, the friction coefficient is strongly enhanced for all volume concentration. For the same Reynolds number, the friction ratio increases while the volume concentration increases.

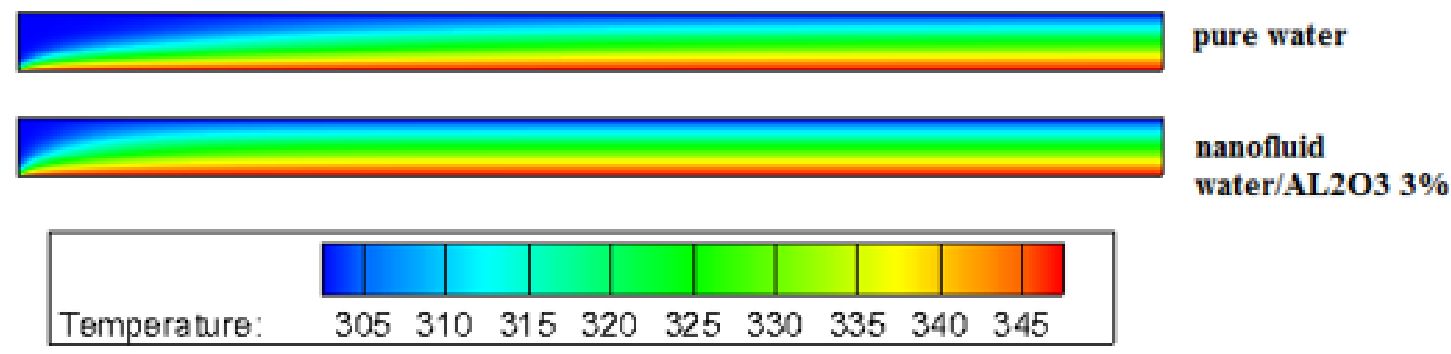

Figure 8. The temperature distribution in microchannels with pure water and nanofluid. 


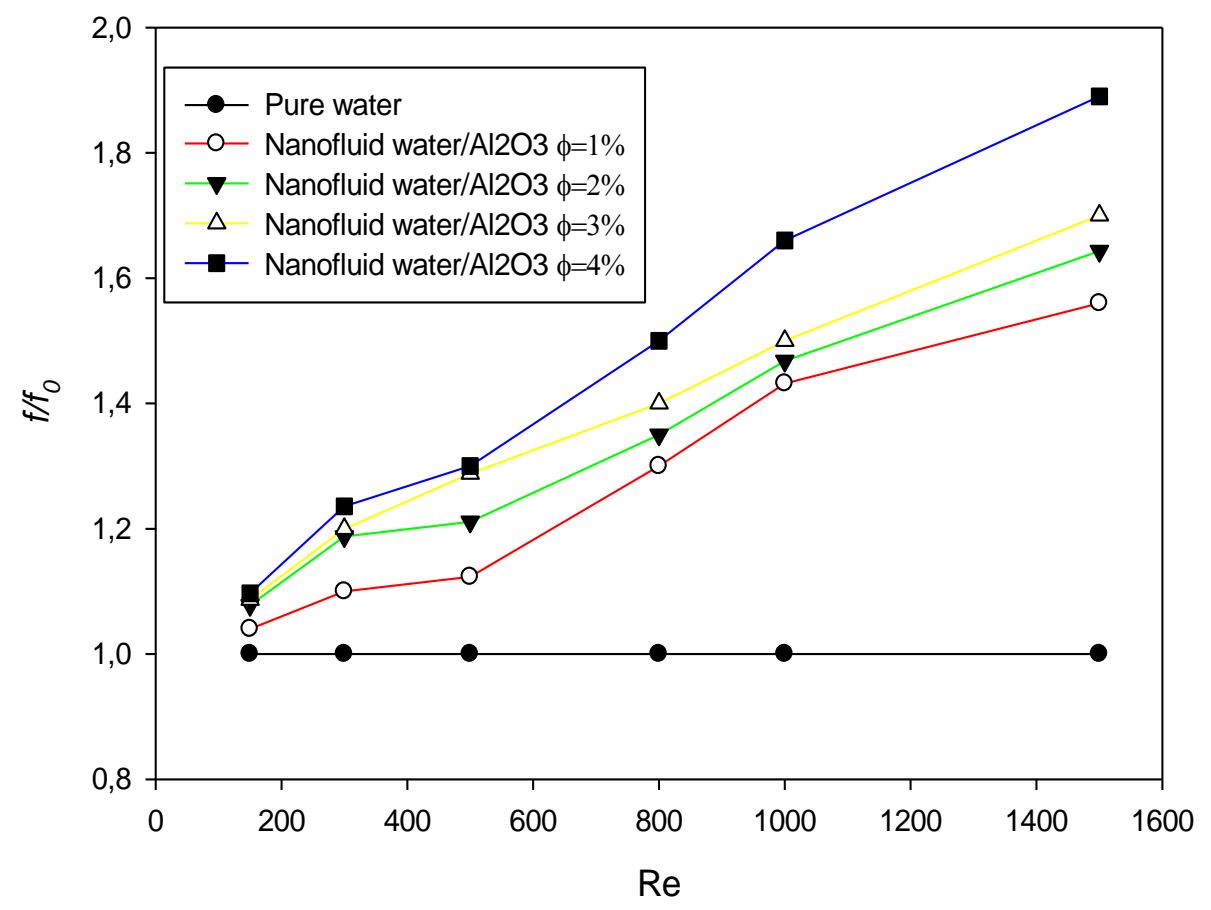

Figure 9. Effect of nanoparticles concentration on the friction coefficient

\section{CONCLUSION}

In this paper, a numerical investigation of laminar, forced convective fully developed flow of water/ $\mathrm{Al}_{2} \mathrm{O}_{3}$ nanofluid has been elaborated in order to enhance the heat transfer in microchannels heat sinks, which allows the following findings and remarks:

- $\quad$ Nusselt number and friction coefficient increase with the increase of Reynolds number

- $\quad$ The nanofluid enhances the heat transfer in reference to pure fluid.

- $\quad$ The increase of nanoparticles concentration $(\phi)$ increases the average Nusselt number for laminar flows

- The increase of nanoparticles concentration $(\phi)$ enhances the friction coefficient.

\section{NOMENCLATURE}

A aspect ratio of the channel (L/D)

D width of the channel, $m$

Cp specific heat, J kg-1 K-1

g gravitational acceleration, $\mathrm{m} \mathrm{s}-2$

Gr Grashof number, g $\beta f$ D3 (Tw-T0)/vf2

$\mathrm{k}$ thermal conductivity, $\mathrm{W}$ m-1 K-1

$\mathrm{L} \quad$ legth of the channel, $\mathrm{m}$

$\mathrm{H} \quad$ height of the channel, $\mathrm{m}$

h convective heat coefficient $\mathrm{W} /(\mathrm{m} 2 \mathrm{~K})$

$\mathrm{Nu} \quad$ Nusselt number

$\mathrm{p} \quad$ fluid pressure, $\mathrm{Pa}$

$\operatorname{Pr} \quad$ Prandtl number, of $/ \alpha f$

Re Reynolds number

$\mathrm{T}$ temperature, $\mathrm{K}$

$\mathrm{U} \quad$ velocity, $\mathrm{m} \mathrm{s}-1$

$\mathrm{u}, \mathrm{v} \quad$ velocity components in $\mathrm{x}, \mathrm{y}$ directions,ms-1

$\mathrm{x}, \mathrm{y} \quad$ Cartesian coordinates, $\mathrm{m}$ 


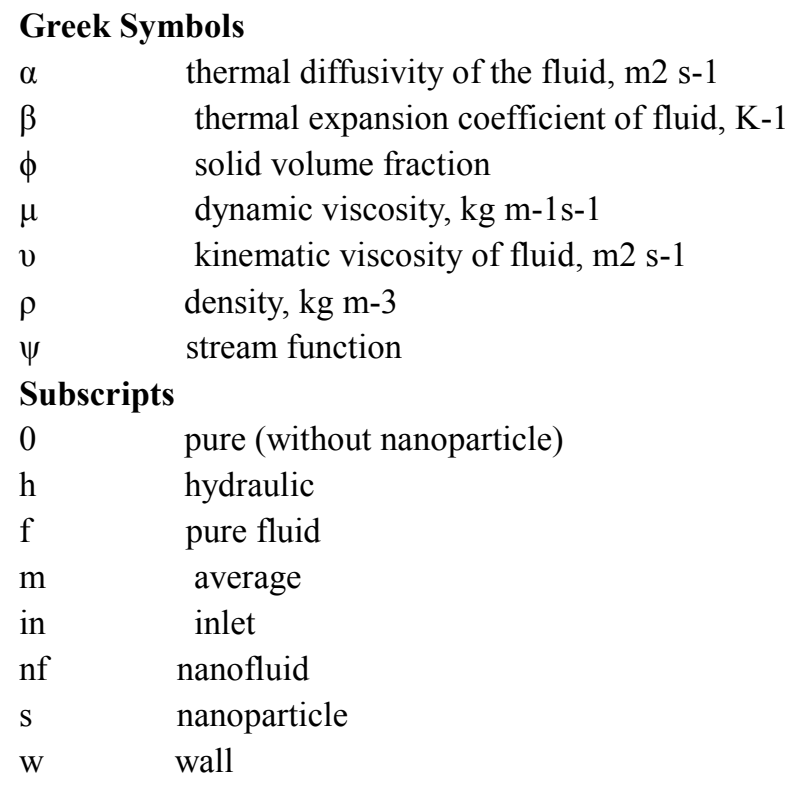

\section{REFERENCES}

[1] Tuckerman, D. B., Pease, R. F. W. (1981). High-performance heat sinking for VLSI. IEEE Electron Device Letters, 2(5), 126-129.

[2] Chai, L., Xia, G., Zhou, M., Li, J., Qi, J. (2013). Optimum thermal design of interrupted microchannel heat sink with rectangular ribs in the transverse microchambers. Applied Thermal Engineering, 51(1-2), 880-889.

[3] Weilin, Q., Mala, G. M., Dongqing, L. (2000). Pressure-driven water flows in trapezoidal silicon microchannels. International Journal of Heat and Mass Transfer, 43(3), 353-364.

[4] Gururatana, S. (2012). Numerical simulation of micro-channel heat sink with dimpled surfaces. American Journal of Applied Sciences, 9(3), 399.

[5] Belhadj, A., Bouchenafa, R., Saim, R. (2018). A Numerical study of forced convective flow in microchannels heat sinks with periodic expansion-constriction cross section. Journal of Thermal Engineering, 4(3), 1912-1925.

[6] Belhadj. A, Etude Thermo-énergétique d'un écoulement convective forcé à l'intérieur des microcanaux, Thèse de Master, 2014, Université de Tlemcen, Algeria.

[7] Masuda, H., Ebata, A., Teramae, K. (1993). Alteration of thermal conductivity and viscosity of liquid by dispersing ultra-fine particles. Dispersion of $\mathrm{Al}_{2} \mathrm{O}_{3}, \mathrm{SiO}_{2}$ and $\mathrm{TiO}_{2}$ ultra-fine particles. Netsu Bussei 7(4):227-233.

[8] Choi, S. U., Eastman, J. A. (1995). Enhancing thermal conductivity of fluids with nanoparticles (No. ANL/MSD/CP--84938; CONF-951135--29). Argonne National Lab., IL (United States).

[9] Pak, B. C., Cho, Y. I. (1998). Hydrodynamic and heat transfer study of dispersed fluids with submicron metallic oxide particles. Experimental Heat Transfer, 11(2), 151-170.

[10] Das, S. K., Putra, N., Thiesen, P., Roetzel, W. (2003). Temperature dependence of thermal conductivity enhancement for nanofluids. Journal of Heat Transfer, 125(4), 567-574.

[11] Li, J. (2008). Computational analysis of nanofluid flow in microchannels with applications to micro-heat sinks and bio-MEMS.PhD Thesis.

[12] Raisi, A., Ghasemi, B., Aminossadati, S. M. (2011). A numerical study on the forced convection of laminar nanofluid in a microchannel with both slip and no-slip conditions. Numerical Heat Transfer, Part A: Applications, 59(2), 114-129.

[13] Murshed, S. S., Leong, K. C., Yang, C., Nguyen, N. T. (2008). Convective heat transfer characteristics of aqueous $\mathrm{TiO}_{2}$ nanofluid under laminar flow conditions. International Journal of Nanoscience, 7(06), 325-331.

[14] Izadi, M., Shahmardan, M. M., Rashidi, A. M. (2013). Study on thermal and hydrodynamic indexes of a nanofluid flow in a micro heat sink. Transport Phenomena in Nano and Micro Scale, 1(1), 53-63

[15] Izadi, M., Shahmardan, M. M., Rashidi, A. M. (2013). Study on thermal and hydrodynamic indexes of a nanofluid flow in a micro heat sink. Transport Phenomena in Nano and Micro Scale, 1(1), 53-63. 
[16] Estellé, P., Halelfadl, S., Maré, T. (2015). Thermal conductivity of CNT water based nanofluids: Experimental trends and models overview. Journal of Thermal Enginnering, 1(2), 381-390.

[17] Kherbeet, A. S., Mohammed, H. A., Salman, B. H., Ahmed, H. E., Alawi, O. A., Rashidi, M. M. (2015). Experimental study of nanofluid flow and heat transfer over microscale backward-and forward-facing steps. Experimental Thermal and Fluid Science, 65, 13-21.

[18] Kalteh, M., Abbassi, A., Saffar-Avval, M., Frijns, A., Darhuber, A., Harting, J. (2012). Experimental and numerical investigation of nanofluid forced convection inside a wide microchannel heat sink. Applied Thermal Engineering, 36, 260-268.

[19] İlhan, B., Ertürk, H. (2017). Experimental characterization of laminar forced convection of hBN-water nanofluid in circular pipe. International Journal of Heat and Mass Transfer, 111, 500-507.

[20] Li, P., Xie, Y., Zhang, D., Xie, G. (2016). Heat transfer enhancement and entropy generation of nanofluids laminar convection in microchannels with flow control devices. Entropy, 18(4), 134.

[21] Jajja, S. A., Ali, W., Ali, H. M., Ali, A. M. (2014). Water cooled minichannel heat sinks for microprocessor cooling: Effect of fin spacing. Applied Thermal Engineering, 64(1-2), 76-82.

[22] Ali, H. M., Arshad, W. (2017). Effect of channel angle of pin-fin heat sink on heat transfer performance using water based graphene nanoplatelets nanofluids. International Journal of Heat and Mass Transfer, 106, 465-472.

[23] Arshad, W., Ali, H. M. (2017). Graphene nanoplatelets nanofluids thermal and hydrodynamic performance on integral fin heat sink. International Journal of Heat and Mass Transfer, 107, 995-1001.

[24] Togun, H. (2016). Laminar CuO-water nano-fluid flow and heat transfer in a backward-facing step with and without obstacle. Applied Nanoscience, 6(3), 371-378. 